\title{
Troy Ounce
}

National Cancer Institute

\section{Source}

National Cancer Institute. Troy Ounce. NCI Thesaurus. Code C64558.

The non-SI unit of mass equal to 31.103 grams, 20 pennyweight, or 480 grains, or 0.083 pound. 